\section{Enhanced Uptake of 10\% Ascorbic Acid After I440-nm or 1927-nm Non-ablative Fractional Diode Laser Treatment}

\section{OBJECTIVE}

- To quantify uptake of $10 \%$ ascorbic acid following pretreatment with low-power I 440-nm or 1927-nm non-ablative fractional diode lasers (Clear + Brilliant ${ }^{\circledR}$ laser system; Solta Medical, Bothell, WA) with varying treatment densities

\section{CONCLUSIONS}

- In this ex vivo analysis, the greatest enhancement of $10 \%$ ascorbic acid uptake was seen with 1927-nm pretreatment at $320 \mathrm{MTZ} / \mathrm{cm}^{2}$ and $\mathrm{I} .0 \mathrm{~W}$, compared to 1 440-nm wavelengths at varying wattage and treatment densities

- This provides a foundation for clinical studies on laser-enhanced uptake of ascorbic acid and other topicals, which can allow clinicians to better understand the relationship between quantifiable uptake enhancement and patientcentered outcomes
Jordan V.Wang, MD, MBE, MBA'; Paul M. Friedman, MD'; ; Adarsh Konda, PharmD; Catherine Parker, NP, MSN; Roy G. Geronemus, MD' Laser \& Skin Surgery Center of New York, New York, NY; 'Dermatology and Laser Surgery Center, Houston, TX; Bausch Health US, LLC, Bridgewater, Nj; 'Solta Medical, Bothell,WA

\section{SYNOPSIS}

- The stratum corneum forms a vital protective barrier along the outer layer of the skin, but also prevents optimal uptake of topical formulations

- Lasers can facilitate better penetration and absorption of topicals by disrupting the stratum corneum and tight junctions in the epidermis ${ }^{2}$

- Non-ablative lasers generally target dermal tissue and largely spare the stratum corneum, which minimizes overall thermal side effects and postprocedural recovery time, while fractionation further

- The relationship between topical uptake and laser device settings, such as wavelength, peak power, and spot density, must be quantified to optimize treatment benefits

\section{METHODS}

- Excised human abdominal skin samples of 500-um thickness were pretreated with a $1440-\mathrm{nm}$
laser with 80 microscopic treatment zones (MTZ)/(cm $(1.2 \mathrm{~W}), 1440-\mathrm{nm}$ laser with $320 \mathrm{MTZ} / \mathrm{cm}^{2}$ laser with 80 microscopic treatment zones (MTZ)/cm ${ }^{2}(1.2 \mathrm{~W}), 1440$-nm laser with $320 \mathrm{MTZ} / \mathrm{cm}^{2}$
$(3 \mathrm{~W}), 1927-\mathrm{nm}$ laser with $320 \mathrm{MTZ} / \mathrm{cm}^{2}(\mathrm{I} \mathrm{W})$, or received no pretreatment (Table I)

Table I. Experimental Parameters

\begin{tabular}{|lccc|}
\hline Parameter & \multicolumn{3}{c|}{ Setting } \\
\hline Device wavelength, $n \mathrm{~nm}$ & 1440 & 1440 & 1927 \\
\hline Spot density, $M T Z / \mathrm{cm}^{2}$ & 80 & 320 & 320 \\
\hline Peak power, $\mathrm{W}$ & 1.2 & 3 & 1 \\
\hline Spot size, $\mathrm{mm}$ & 130 & 130 & 130 \\
\hline Pulse energy, $\mathrm{m}]$ & 9 & 9 & 9 \\
\hline MTZ, microscopic creatment zones. & & & \\
\hline
\end{tabular}

Following laser pretreatment, $10 \%$ ascorbic acid (Obagiं, Long Beach, CA; 2010 formulation)
was applied, and permeation was measured up to 24 hours after application (Figure I)

Samples were fittered and analyzed using high-performance liquid chromatography to measure
topical permeation and retention for laser-treated samples and untreated controls

- Total uptake was calculated as the sum of the normalized cumulative permeation and

- Average total uptake was compared between laser-treated samples and untreated controls to
determine the uptake enhancement ratio

Figure I. Study design for testing uptake of topicals on skin tissue.

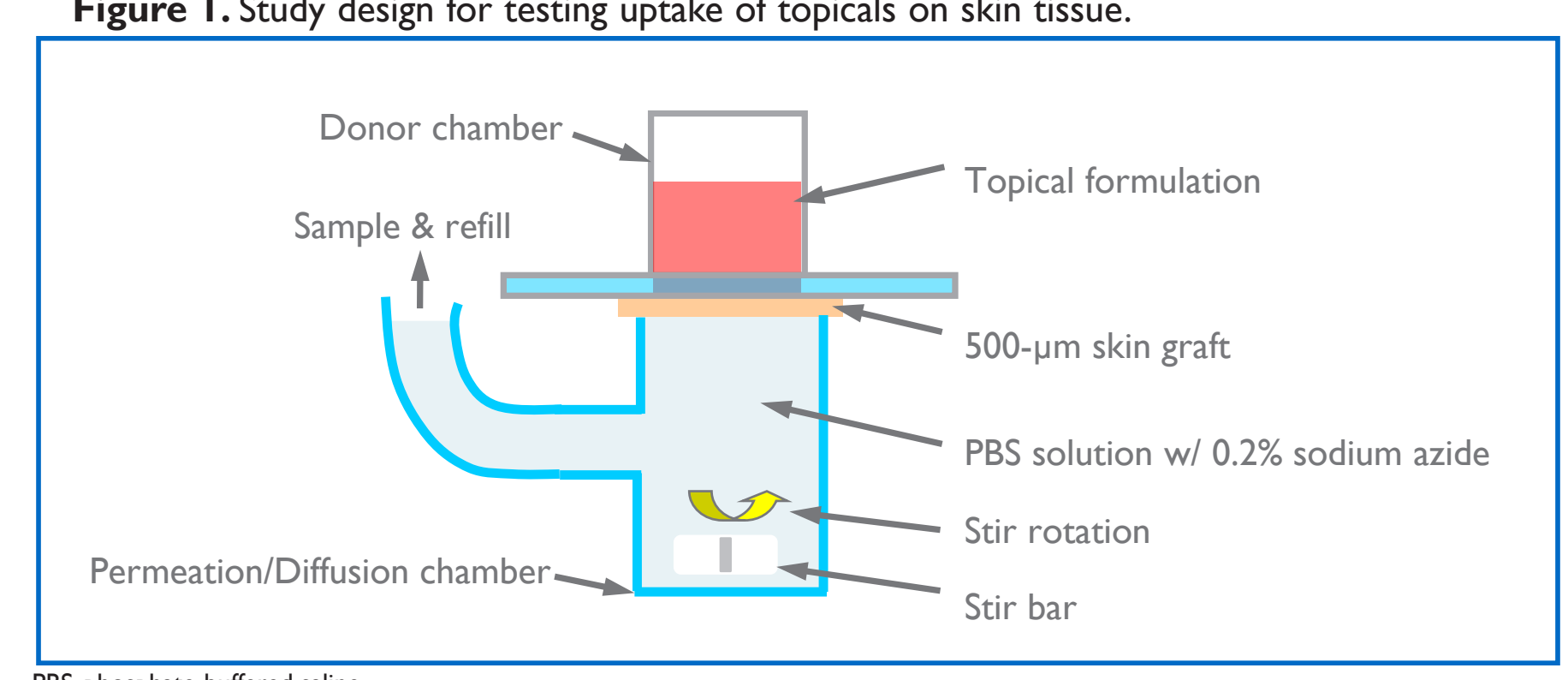

BS, phosphate-buffered saline.

Presented at the 2021 Fall Clinical Dermatology Conference • October 21-24, 2021 • Las Vegas, NV, and Virtual
RESULTS

Permeation

- Pretreatment with the $1927-\mathrm{nm}$ laser with $320 \mathrm{MTZ} / \mathrm{cm}^{2}$ enhanced permeation of $10 \%$ ascorbic acid at 24 hours posttreatment relative to other pretreatments and untreated control (Figure 2) Figure 2. Cumulative permeation of $10 \%$ ascorbic acid after laser pretreatment.

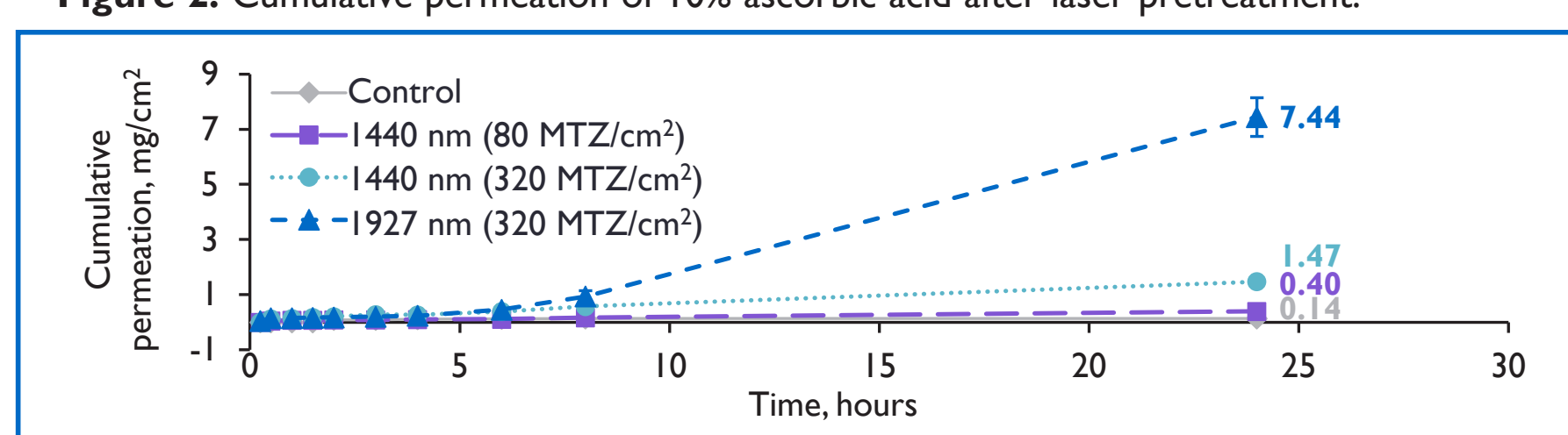

Values are mean \pm standard deviation. MTZ, microscopic treatment zones.

Uptake

- Pretreatment with the $1927-n m$ laser with $320 \mathrm{MTZ} / \mathrm{cm}^{2}$ enhanced uptake by $>4$ times compared to the $1440-\mathrm{nm}$ laser with $320 \mathrm{MTZ} / \mathrm{cm}^{2}\left(7.8 \mathrm{vs} 1.8 \mathrm{mg} / \mathrm{cm}^{2} ;\right.$ Table 2$)$ Conced

- Pretreatment with the $1440-\mathrm{nm}$ laser with $320 \mathrm{MTZ} / \mathrm{cm}^{2}$ was associated with 3 -times greater uptake compared to the $1440-\mathrm{nm}$ laser with $80 \mathrm{MTZ} / \mathrm{cm}^{2}\left(1.8 \mathrm{vs} 0.5 \mathrm{mg} / \mathrm{cm}^{2}\right)$ $>7$-times greater uptake compared to untreated control $\left(1.8 \mathrm{vs} 0.2 \mathrm{mg} / \mathrm{cm}^{2}\right)$ Table 2. Uptake Ratios of 10\% Ascorbic Acid

\begin{tabular}{|lccc|}
\hline & $1440 \mathrm{~nm}\left(80 \mathrm{MTZ} / \mathrm{cm}^{2}\right)$ & $1440 \mathrm{~nm}\left(320 \mathrm{MTZ} / \mathrm{cm}^{2}\right)$ & $1927 \mathrm{~nm}\left(320 \mathrm{MTZ} / \mathrm{cm}^{2}\right)$ \\
\hline Control & $2.18 \pm 0.55 \times$ & $7.75 \pm 2.02 \times$ & $33.61 \pm 0.02 \times$ \\
\hline $1440 \mathrm{~nm}\left(80 \mathrm{MTZ} / \mathrm{cm}^{2}\right)$ & - & $3.56 \pm 0.70 \times$ & $15.45 \pm 0.02 \times$ \\
\hline $144 \mathrm{~nm}\left(320 \mathrm{MTZ} / \mathrm{cm}^{2}\right)$ & - & - & $4.34 \pm 0.07 \times$ \\
\hline Values are mean \pm r rot mean square. $\mathrm{MTZ}$, microscopic treatment zones. & & \\
\hline
\end{tabular}

Funding information: This study was sponsored by Solta Medical. Medical writing support was provided by MedThink
Scicom and funded by Solta Medical. Disclosures: $\mathrm{JWW}$ is an investigator for Solta Medical. PMF serves on the advisory board and speaker bureau for Solta Medical.
AK and CP are employeees of and may hold stock or stock options in Solta Medical. RGG is an investigator and advisory board
member for Solta Medical.

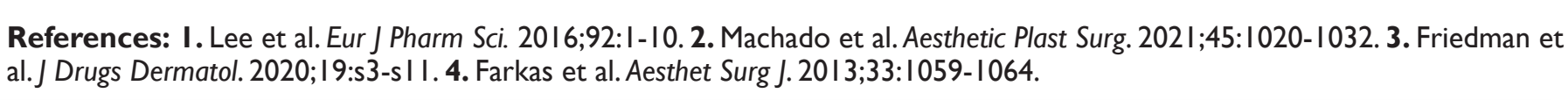

1

